\section{Impact of vaccination on the incidence of measles in Mozambique in the period 2000 to 2011}

\author{
Impacto da vacinação sobre a incidência \\ de sarampo em Moçambique no \\ período de 2000-2011
}

Impacto de la vacunación sobre la incidencia
del sarampión en Mozambique durante
el período de 2000-2011

1 Ministério da Saúde, Maputo, Moçambique,

2 Escola Nacional de Saúde Pública Sergio Arouca,

Fundação Oswaldo Cruz,

Rio de Janeiro, Brasil.

Correspondence

A. M. Muloliwa

Ministério da Saúde.

Av. Eduardo Mondlane /

Salvador Allende, Maputo,

MOZ - 264, Moçambique.

muloliwa@yahoo.com.br

\begin{abstract}
The aim of this study was to contribute to the better planning of measles elimination actions in Mozambique, by considering the impact of vaccination actions over the period 2000 to 2011. Descriptive and ecological studies and case records made available by the Ministry of Health were used to analyze measles vaccination coverage. Statistical analysis was performed using time series and spatial analysis. Vaccine coverage rates ranged from $82 \%$ to $99 \%$. Coverage rates in $\mathrm{Ma}$ puto city were under $70 \%$ and in Niassa province they were over 100\%. Coverage showed a clustered pattern in the districts. The measles incidence rate was 1.58 per 100,000 inhabitants (0.00-40.08 per 100,000 inhabitants); districts bordering neighboring countries presented high incidence rates. Although measles morbidity and mortality has decreased in Mozambique, vaccine coverage has been insufficient to interrupt measles transmission. Enhanced surveillance, including investigation of cases and outbreaks, and improvements in measles vaccination are recommended in order to achieve a homogenous coverage rate of $\geq 95 \%$ for both routine and mass vaccination campaigns.
\end{abstract}

Measles; Vaccination; Immunization Coverage
Artur Manuel Muloliwa 1 Luiz Antonio Bastos Camacho 2 José Fernando Souza Verani 2 Taynãna César Simões 2 Martinho do Carmo Dgedge 1

\section{Resumo}

O objetivo deste estudo foi analisar as ações de eliminação do sarampo em Moçambique, considerando o impacto do programa de vacinação ao longo do período de 2000-2011. Foram revisados os dados de vacinação e os casos de sarampo disponíveis no Ministério da Saúde. Análise de séries temporais e técnicas estatísticas de análise espacial foram aplicadas. As coberturas variaram entre $82 \%$ e 99\%. Nas províncias, a cidade de Maputo teve as coberturas abaixo de $70 \%$, e a província de Niassa teve as coberturas acima de $100 \%$. As coberturas apresentaram um padrão espacial que se modificou com o tempo. A taxa de incidência de sarampo no país foi de 1,58 (0,00-40,08 distritos) por 100 mil habitantes. Os distritos que fazem fronteiras com os países vizinhos tiveram as elevadas taxas de incidência. As coberturas de rotina são insuficientes, e a circulação de sarampo continua em Moçambique. O país necessita alcançar coberturas homogêneas e maiores que 95\% em crianças menores de um ano, manter as campanhas de vacinação e melhorar a vigilância e o tratamento de casos.

Sarampo; Vacinação; Cobertura Vacinal 
Introduction

Measles is a highly contagious disease 1,2 caused by infection with a virus belonging to the genus Morbillivirus of the family Paramyxoviridae 3 . The infection manifests itself clinically as fever and exanthema, followed by coughing, conjunctivitis or coryza 2,4,5. Deaths can occur as a result of complications such as pneumonia, diarrhea, malnutrition, middle ear infection and encephalitis. Permanent neurological sequels can also occur, including deafness and blindness 2,6.

Vaccination with a safe and effective vaccine which has been available since the beginning of the 1960s is the most cost-effective public health intervention for preventing this disease 4,6 . In 2001, countries covered by the World Health Organization Regional Office for Africa (WHO/ AFRO) were included in a global initiative to reduce the number of deaths from this disease 7 . Strategies adopted to reduce measles mortality in Africa include routine vaccination with a national first dose coverage target of $90 \% 7,8$ in children under one year of age. This strategy is complemented with mass vaccination campaigns, case-based surveillance with laboratory support, and the correct diagnosis and treatment of cases $7,8,9,10$. Around one million cases of measles were notified annually in the WHO/AFRO region in the early 1980s. After the implementation of measles control activities, estimated annual notification decreased to 300,000 cases in the 1990s and from 492,116 to 32,278 cases in the period 2001 to 2008 7. During the latter period, 398 million children were vaccinated during campaigns in the region and routine first dose coverage increased from $57 \%$ to $73 \%$.

Measles vaccination was introduced in Mozambique in the late 1970s 4,11 and is offered by the public National Health System network to children from the age of nine months 5,11 . Vaccination campaigns were implemented in this country between July and September 2005 4,5, in October 2008 and in May 2011. The availability of data on vaccine coverage and disease occurrence provides the opportunity for in-depth analysis to obtain insights into disease control strategies.

The objective of this study was to analyze the measles situation in Mozambique with reference to disease control actions performed in the period 2000 to 2011 based on data from the country's information system. The ultimate aim is to analyze 7 and document the impact of vaccination strategies on measles morbidity and mortality over the last decade and contribute to better planning of future control actions.

\section{Methods}

\section{Population and place of study}

Mozambique is located in eastern Africa and borders South Africa, Swaziland, Zimbabwe, Zambia, Malawi, Tanzania and the Indian Ocean. The country has a population of 20,530,714 (2007 Census) and an area of $799,380 \mathrm{Km}^{2}$ (population density of 25.7 inhabitants $/ \mathrm{Km}^{2}$ ) divided into 11 provinces and 144 districts. Women account for $52.3 \%$ of the total population, and $23 \%$ of the population lives in urban areas. Four percent of the population is under one year of age and $44.5 \%$ is under the age of 15 years. The population growth rate of Mozambique in the last decade was $2.4 \%$ (Instituto Nacional de Estatística de Moçambique; http://www.ine.gov.mz, accessed on 20/Jun/2011).

\section{Type of study}

A descriptive and ecological study of secondary data was conducted to analyze measles vaccination coverage and cases recorded by the health information system during the period 2000 to 2011.

\section{Data source and collection}

The data used in this study was obtained from the national Health Information System (HIS) $4,12,13$. Data regarding vaccinated children and measles cases observed in outpatients and inpatient wards is compiled and recorded by individual Health Units (HU) and sent to the district health body on a monthly basis (in the case of vaccinations) and weekly basis (for cases of measles and deaths).

The measles vaccine is administered from the age of 9 months, and the calculation of routine vaccination coverage is based on the proportion of children under one year of age that receive the vaccine 14 . However, the age groups targeted by campaigns have varied over the years; in 2005, the target group was children aged nine months to 14 years, in 2008 it was children aged nine to 59 months, and in 2011 it was children aged six to 59 months.

Health Units use the Weekly Epidemiological Bulletin (WEB) 4 to notify measles cases in the following age groups: under nine months, nine to 23 months, and over 23 months. Children in the nine to 23 month age group are categorized into vaccinated and not vaccinated. At district level, Health Unit data is aggregated into a single standardized form which is sent to the provincial health body where it is inputted into the Basic 
Module (BM) database. BM data is sent to the national Ministry of Health by email or in a mobile storage unit, such as a compact disk or flash drive. The BM is updated by the Department of Health Information System (DHIS) of the National Cooperation and Planning Directorate (NCPD). Complementary data is also available from the investigation of individual measles cases which began in 2006 and provides information about gender, place of residence, age, vaccination status and measles and rubella (IgM) serology results. This information is recorded on a database maintained by the Epidemiology Department (ED) of the National Public Health Directorate (NPHD). Data regarding vaccination campaign coverage was obtained from reports available from the Expanded Program on Immunization (EPI), and the size of the population used to calculate rates was obtained from the 1997 Census population projection, available from the BM.

Population projections are made by the $\mathrm{Na}$ tional Statistics Institute (NSI), an independent state organ of the Ministry of Health. National, regional and local measles control goals are stipulated by the Ministry of Health. A clinical and laboratory diagnosis of the disease is performed and cases are notified when fever and generalized exanthema is present together with one of the following symptoms: cough, coryza or conjunctivitis. A positive laboratory diagnosis of the disease is determined by the presence of IgM in a serum sample collected within 28 days after the onset of exanthema 15 . This current definition was introduced in 2006, when case investigation began with laboratory support. Previously, the clinical definition of measles was a high fever (102 to $104^{\circ} \mathrm{F}$ ) with exanthema, accompanied by a cough, coryza or conjunctivitis 4,5 . Data forms were reviewed to remove inconsistent and duplicated data 16 and vaccinations of individuals diagnosed with measles receiving the vaccine within 30 days prior to the collection of the serum sample were excluded 15 .

\section{Data processing and analysis}

The study analyzed trends and variations in measles vaccination coverage and incidence of cases of the disease in all provinces during the period 2000 to 2010. At district level, coverage in 2003, 2006 and 2009 was analyzed through exploratory analysis of mapping and spatial autocorrelation indices. The Global Moran's Index was estimated and tested for each year to detect spatial heterogeneity in the coverage distribution.

The Global Moran's Index value generally varies between -1 to $+117,18$, where +1 indicates a high degree of clustering and - 1 indicates a high degree of dispersion ${ }^{18}$. After detecting global spatial autocorrelation, Local Indices of Spatial Autocorrelation (LISA) were calculated to identify local clusters in districts 17,18 . Tests of statistical significance of spatial autocorrelation were based on 999 permutations of the spatial configuration of the original map of the district under the null hypothesis of spatial homogeneity of coverage of the measles vaccine; the neighborhood matrix was determined according to spatial contiguity based on shared borders 16 .

Local indices were mapped to detect the spatial autocorrelation of coverage. Districts were clustered into five groups according to their statistical significance and location in the Moran Scatter plot quadrants: 0 for districts with statistically insignificant spatial correlation; Quadrant-1 for districts with high coverage rates and whose neighboring districts also have high coverage rates; Quadrant-2 for districts with low coverage rates and whose neighboring districts also have low coverage rates; Quadrant-3 for districts with high coverage rates and whose neighboring districts have low coverage rates; and Quadrant-4 for districts with low coverage rates and whose neighboring districts have high coverage rates 17 .

For mapping, crude measles vaccine coverage was classified into three categories: (1) coverage below $80 \%$; (2) coverage from 80 to $95 \%$; and (3) coverage equal to or greater than $95 \%$.

Information on routine vaccination was complemented with the results of the 2005, 2008 and 2011 vaccination campaigns.

Descriptive graphs of the time series were used to detect important trends and variations in the notification of measles cases and deaths recorded in the period 2003 to 2010. In addition, average annual provincial notification rates were compared in the three periods preceding a vaccination campaign: 2003 to 2004, 2006 to 2007, and 2009 to 2010. The average annual notification rate (AANR) was calculated based on the following formula:

$$
\text { AANR }=\frac{\frac{\sum \text { cases reported in the period }}{\text { number of years in the period }}}{\text { population of one year of the period }} \times 100,000
$$

The population used in the denominator was from the years 2004, 2007 and 2010 to the respective notification rate period. The Crude Annual Incidence Rate (CAIR) was estimated for each district based on measles cases confirmed by laboratory or epidemiological diagnoses during the period 2006 to 2010 using the following formula: 
$\Sigma$ cases reported in the period

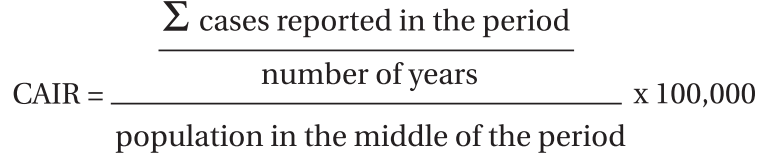

The population of the middle of the period was that of 2008. Due to the high variability of incidence rates, especially in provinces where only a small population was at risk of contracting the disease, these rates were adjusted according to neighboring district rates using the Bayesian Empirical Rates 18. A thematic map of crude incidence rates was elaborated. To differentiate districts, incidence rates were organized into the following categories: low (0-50\%), medium (50$75 \%)$ and high (75-100\%) and spatial autocorrelation analysis (Global Moran Index) was conducted according to these categories. Confirmed measles cases were characterized according to their distribution by age group, gender, place of residence and vaccination status.

Spatial analysis was performed using the software TerraView 3.2.0 (Instituto Nacional de Pesquisas Espaciais, São José dos Campos, Brazil; http://www.dpi.inpe.br/terraview) and statistical analysis was conducted using the software R version 2.11.1 (The R Foundation for Statistical Computing, Vienna, Austria; http:// www.r-project.org).

The study used secondary data and did not involve the direct participation of individuals. Before data collection, the research team received institutional authorization to access information and the project was submitted and approved by the research ethics committees of the Brazilian National School of Public Health/Oswaldo Cruz Foundation (document number 20/10) and of the Ministry of Health of Mozambique (document number 108/CNBS/2010).

\section{Results}

\section{Routine vaccination coverage}

Table 1 shows that national routine vaccination coverage in children under one year of age was between $82 \%$ and $99 \%$ in the period 2000 to 2011. Although a slight increase in measles vaccination coverage occurred between 2000 and 2005 , coverage of $95 \%$ was not attained. A large rise was observed in 2006 and in the following year measles vaccination coverage and stability reached $99 \%$. In 2008, coverage dropped to $82 \%$, followed by an increase to $95 \%$ in 2011 . Trends in coverage varied according to province. Coverage in Niassa province, in the north of the country, was over $100 \%$ over practically the whole study period, whereas coverage in the City of Maputo, located in the south of the country, was consistently below $70 \%$. Large variations were observed in vaccination coverage in the provinces of Tete and Manica in central Mozambique.

Vaccination coverage in the districts showed a clustered pattern (Figure 1) with a statistically significant Global Moran's Index in the years 2003, 2006 and 2009. The proportion of districts with a crude coverage rate under $80 \%$ was $22.7 \%$ (32/141) in 2003 and the Global Moran's Index was 0.04 ( $\mathrm{p}<0.05)$. The maps demonstrating spatial autocorrelation showed that districts with lower coverage rates were concentrated in the provinces of Cabo Delgado, Maputo and the City of Maputo. In 2006, the proportion of districts with a crude coverage rate of less than $80 \%$ was 9.1\% (13/143), and the Global Moran's Index was 0.26 ( $\mathrm{p}<0.05$ ). The maps demonstrating spatial autocorrelation show that all provinces, except Manica, Sofala and Niassa, had districts with low coverage rates. In 2009, the proportion of districts where coverage was below $80 \%$ grew to $23.6 \%$ (34/144) and the Global Moran's Index was 0.22 $(\mathrm{p}<0.05)$. The maps demonstrating spatial autocorrelation show that all provinces in the center of the country, except Manica and Sofala, had districts with low coverage rates.

\section{Coverage in vaccination campaigns}

Measles vaccination campaigns were conducted in 2005, 2008 and 2011. In the 2005 campaign, $8,189,378$ children, equivalent to $97 \%$ of coverage of children aged 9 months to 14 years, were vaccinated. Rates across provinces varied between $86 \%$ in the City of Maputo to $103 \%$ in Zambezia province. In the 2008 campaign, 3,369,835 children aged nine months to four years, equivalent to $104 \%$ coverage, were vaccinated. Rates varied across provinces from $83 \%$ in Gaza to $138 \%$ in Manica. During the 2011 campaign, 3,985,564 children aged six months to four years, equivalent to $105 \%$ coverage, were vaccinated. The lowest coverage rate occurred in the province of Maputo (96\%) and the highest rate was in the province of Sofala (117\%).

\section{Notification of measles cases and deaths}

Health facilities notified 53,251 cases of measles and 320 deaths during the period 2003 to 2010. Sixteen percent $(8,363)$ of these cases were children aged under nine months, $29 \%(15,324)$ were aged nine to 23 months and $56 \%(29,564)$ were over 23 months. Sixty-six percent $(10,072)$ of children in the nine to 23 month age group were vaccinated. Twenty-seven percent of the 328 deaths 
Table 1

Proportion (\%) of children under one year of age vaccinated against measles by province. Mozambique, 2000-2011.

\begin{tabular}{lcccccccccccc}
\hline Province & $\mathbf{2 0 0 0}$ & $\mathbf{2 0 0 1}$ & $\mathbf{2 0 0 2}$ & $\mathbf{2 0 0 3}$ & $\mathbf{2 0 0 4}$ & $\mathbf{2 0 0 5}$ & $\mathbf{2 0 0 6}$ & $\mathbf{2 0 0 7}$ & $\mathbf{2 0 0 8}$ & $\mathbf{2 0 0 9}$ & $\mathbf{2 0 1 0}$ & $\mathbf{2 0 1 1}$ \\
\hline Niassa & 116 & 115 & 102 & 107 & 119 & 119 & 134 & 129 & 98 & 93 & 127 & 83 \\
Cabo Delgado & 73 & 97 & 85 & 90 & 91 & 93 & 102 & 105 & 96 & 106 & 98 & 88 \\
Nampula & 94 & 101 & 79 & 91 & 87 & 103 & 99 & 102 & 119 & 113 & 103 & 107 \\
Zambézia & 98 & 83 & 88 & 95 & 94 & 90 & 101 & 94 & 63 & 86 & 103 & 97 \\
Tete & 88 & 95 & 126 & 98 & 81 & 64 & 102 & 103 & 83 & 108 & 95 & 142 \\
Manica & 91 & 83 & 86 & 85 & 88 & 85 & 125 & 162 & 70 & 103 & 93 & 82 \\
Sofala & 78 & 77 & 78 & 82 & 78 & 75 & 84 & 84 & 81 & 87 & 87 & 108 \\
Inhambane & 82 & 90 & 93 & 97 & 94 & 85 & 90 & 91 & 76 & 78 & 74 & 81 \\
Gaza & 88 & 95 & 83 & 109 & 102 & 95 & 96 & 93 & 63 & 81 & 72 & 76 \\
Maputo & 78 & 77 & 81 & 85 & 77 & 77 & 92 & 81 & 57 & 79 & 77 & 83 \\
City of Maputo & 31 & 29 & 28 & 30 & 68 & 52 & 63 & 56 & 61 & 52 & 48 & 68 \\
Mozambique & 85 & 86 & 84 & 89 & 89 & 87 & 99 & 99 & 82 & 92 & 91 & 95 \\
\hline
\end{tabular}

Figure 1

Proportion of children under one year of age vaccinated against measles in districts of Mozambique.

1a) Crude coverage (2003)

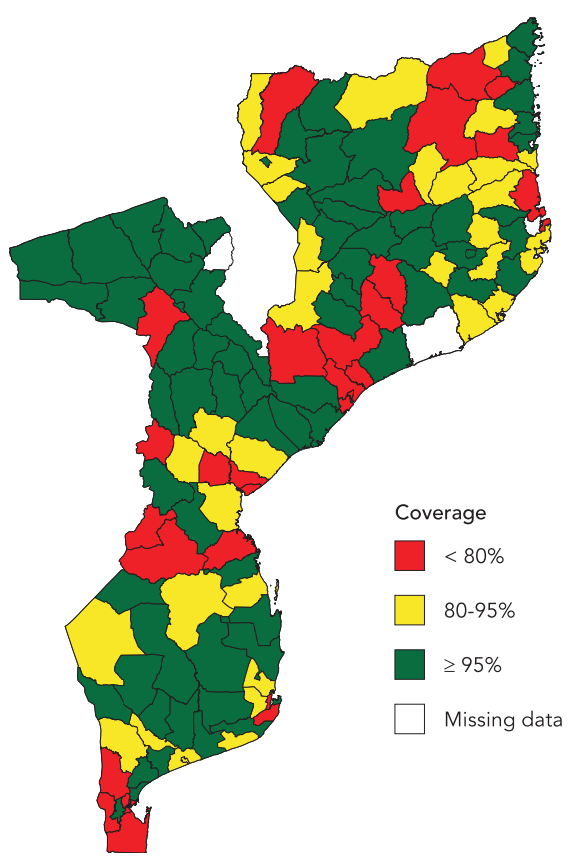

1b) Crude coverage (2006)

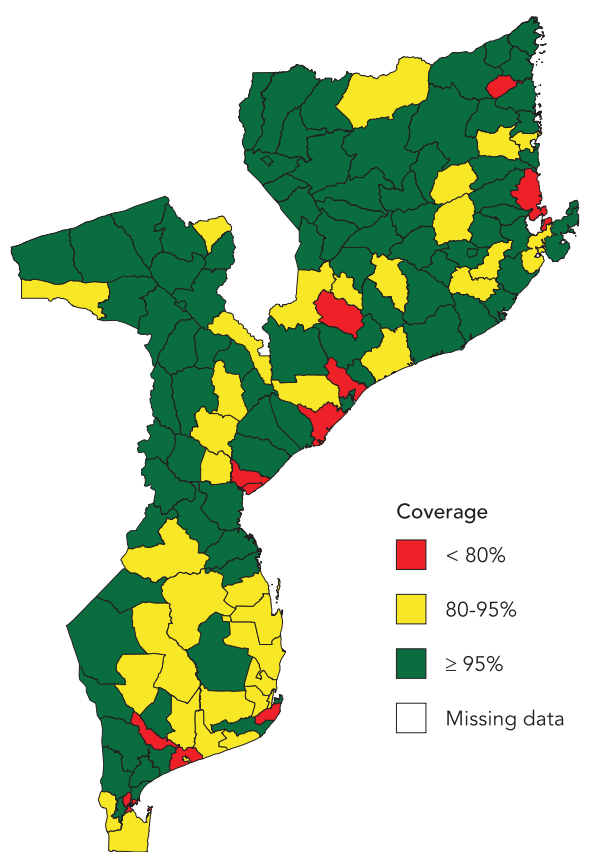

(continues) 
1c) Crude coverage (2009)

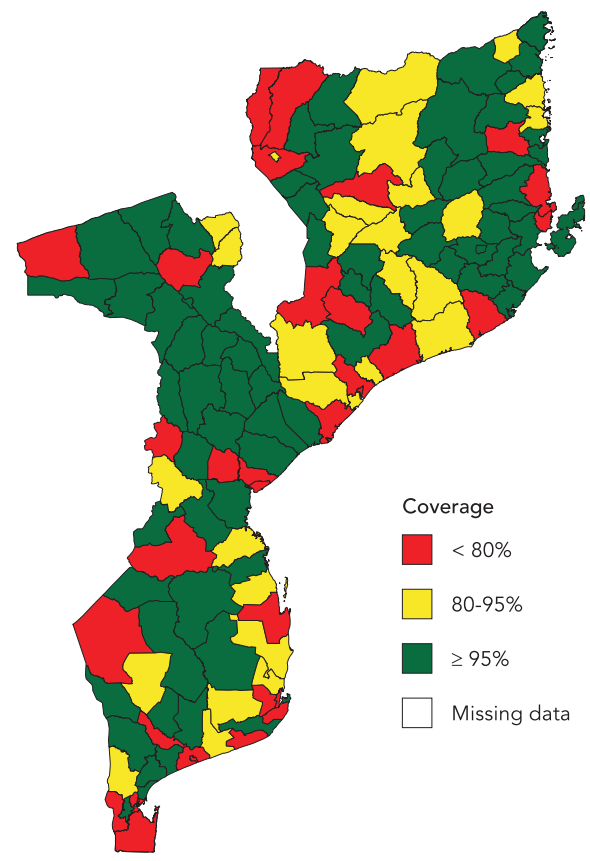

1e) Spatial autocorrelation (2006)

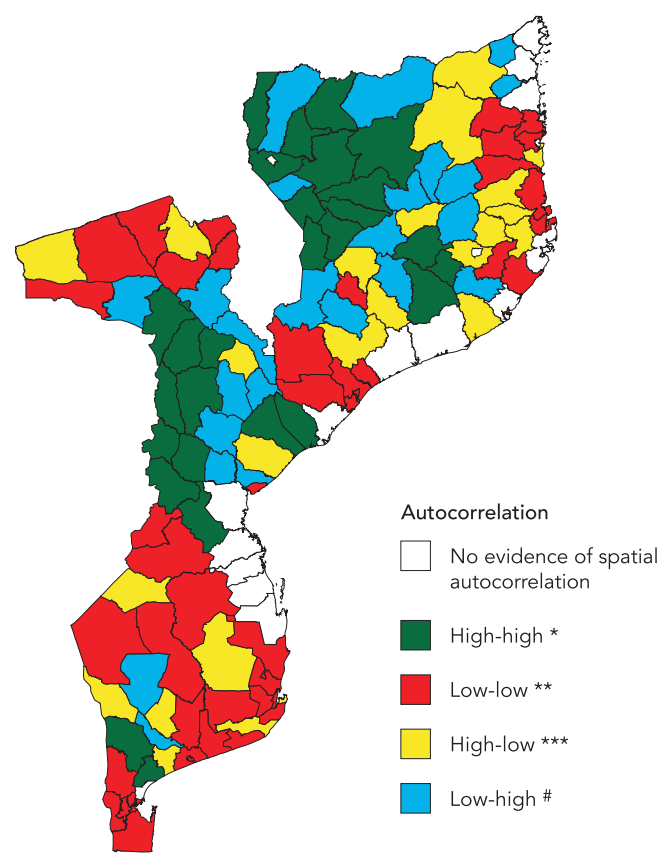

1d) Spatial autocorrelation (2003)

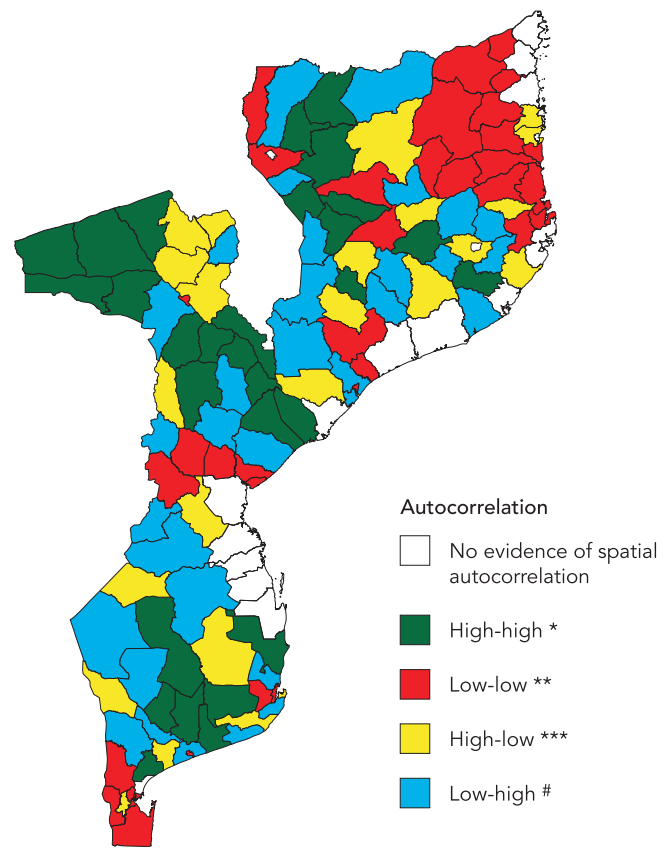

1f) Spatial autocorrelation (2009)

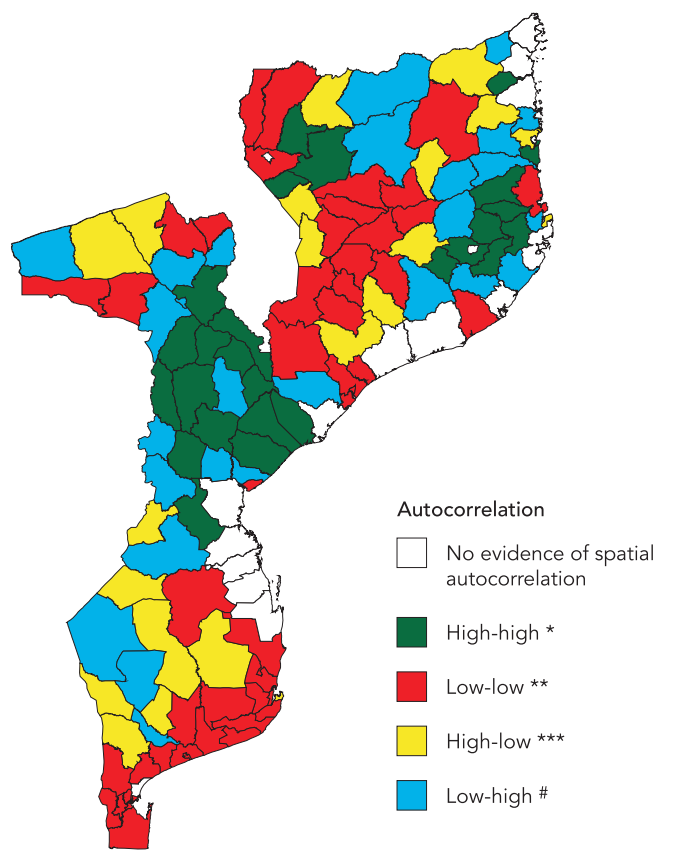

* Districts with high coverage rates and whose neighboring districts also have high coverage rates;

** Districts with low coverage rates and whose neighboring districts also have low coverage rates;

*** Districts with high coverage rates and whose neighboring districts have low coverage rates;

\# Districts with low coverage rates and whose neighboring districts have high coverage rates. 
(85) were children under nine months of age, $25 \%$ (80) were children aged nine to 23 months and $48 \%$ (153) were children over 23 months of age. A time relationship between the observed series of measles cases and deaths during the study period was observed. The curves show two distinct peaks in notifications of cases of measles and deaths in 2003 and 2005. Cases and deaths dropped after the national vaccination campaign in 2005 and remained stable up to 2010, when there was a renewed increase (Figure 2).

Table 2 shows three periods of measles notification and three annual average notification rates. A total of 35,309 measles cases were notified in 2003 and 2004, with the largest number of cases (26\% of the total) being registered in Zambézia province. In 2006 and 2007, the number of notified cases decreased to 479 , with the largest number of cases (27\% of the total) being registered in the City of Maputo and Niassa province. Between 2009 and 2010, the total number of notified measles cases rose to 4,046, with the largest number of cases ( $28 \%$ of the total) being registered in Tete province.

The average annual measles notification rate was 91.9 per 100,000 inhabitants in the period preceding the 2005 campaign. This rate fell to 1.2 per 100,000 inhabitants during the interval be- tween the 2005 and 2008 campaigns and between the 2008 and 2011 campaigns the rate increased slightly to 9.1 cases per 100,000 inhabitants. While the highest average notification rate over the three periods analyzed by this study was recorded in Niassa province, the highest individual notification rates were recorded in the province of Tete in the first and last periods. The lowest average notification rate over the three periods was recorded in the province of Nampula.

\section{Case investigation}

A total of 3,567 suspected measles cases occurring during the period 2006 to 2010 were investigated, of which $41.8 \%(1,492 / 3,567)$ were confirmed by laboratory or by epidemiological diagnosis, $10.5 \%(373 / 3,567)$ were rubella cases and $47.7 \%(1702 / 3,567)$ were discarded. With regard to the measles cases, 4 were confirmed in 2006, 5 in 2007, 2 in 2008, 62 in 2009 and 1,419 in 2010. Information obtained regarding the age of patients in 1,455 of the confirmed cases shows that the age of infected individuals ranged from four days to 56 years (average 9.8 years). Children aged up to five years comprised $49 \%(711 / 1,455)$ of all cases, while children under nine months comprised $16 \%(228 / 1,455)$ of the total. A reduced

Figure 2

Weekly notification of measles cases and measles deaths. Mozambique, 2002-2011.

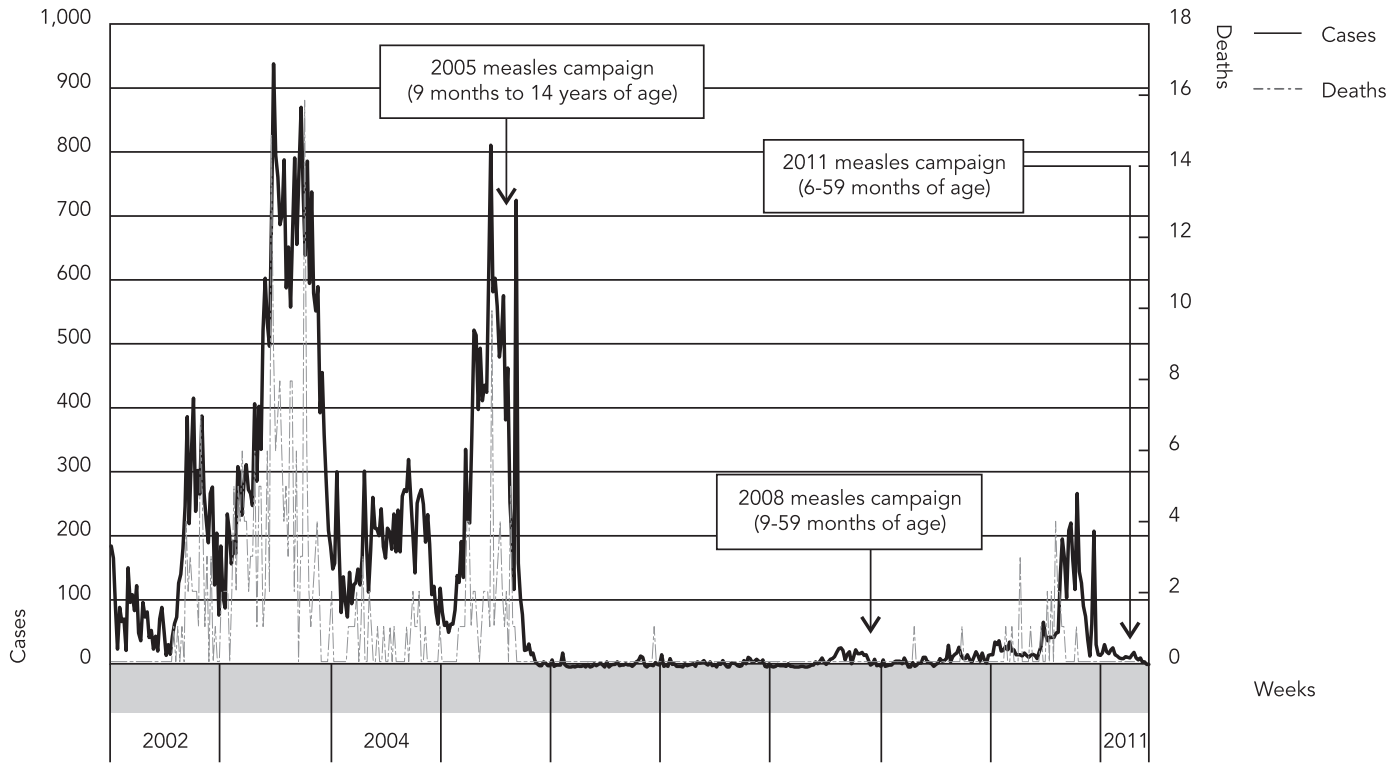


Measles cases and average annual notification rates per 100,000 inhabitants. Mozambique, 2003-2010.

\begin{tabular}{lcccccc}
\hline Province & \multicolumn{3}{c}{ Notified cases } & \multicolumn{4}{c}{ Average annual notification rate } \\
& $\mathbf{2 0 0 3 - 2 0 0 4}$ & $\mathbf{2 0 0 6 - 2 0 0 7}$ & $\mathbf{2 0 0 9 - 2 0 1 0}$ & $\mathbf{2 0 0 3 - 2 0 0 4}$ & $\mathbf{2 0 0 6 - 2 0 0 7}$ & $\mathbf{2 0 0 9 - 2 0 1 0}$ \\
\hline Niassa & 1,988 & 131 & 923 & 102.2 & 6.2 & 40.3 \\
Cabo Delgado & 3,375 & 19 & 74 & 106.5 & 0.6 & 2.1 \\
Nampula & 521 & 65 & 120 & 6.9 & 0.8 & 1.4 \\
Zambézia & 9,185 & 13 & 218 & 123.8 & 0.2 & 2.6 \\
Tete & 3,890 & 0 & 1,138 & 132.1 & 0.0 & 33.0 \\
Manica & 1,507 & 5 & 362 & 58.8 & 0.2 & 11.9 \\
Sofala & 3,710 & 15 & 249 & 115.9 & 0.4 & 6.7 \\
Inhambane & 3,445 & 24 & 207 & 127.6 & 0.8 & 6.7 \\
Gaza & 3,550 & 23 & 103 & 139.0 & 0.8 & 3.5 \\
Maputo & 1,311 & 52 & 173 & 64.4 & 2.4 & 7.4 \\
City of Maputo & 2,827 & 132 & 479 & 118.8 & 5.2 & 14.1 \\
Mozambique & 35,309 & 479 & 4,046 & 91.9 & 1.2 & 9.1 \\
\hline
\end{tabular}

number of cases were observed in the 15-19 year age group that comprised $7 \%(105 / 1,455)$ of total cases, followed by an increase in the 20-24 year age group, representing $9 \%(138 / 1,455)$ of all cases, with significantly less cases in the other age groups (Figure 3$)$. Fifty percent $(744 / 1,485)$ of the total confirmed cases were female and $59 \%$ $(838 / 1,427)$ lived in rural areas. No information on vaccination status was available for the large majority of confirmed cases $(1,363 / 1,492$, equivalent to $91.3 \%$ of all cases). Of the cases where information on vaccination was available, $43.4 \%$ (56/129) had received at least one dose of the measles vaccine. With regard to the geographical distribution of cases, $47.5 \%(708 / 1,492)$ occurred in Tete province, $17.4 \%(260 / 1,492)$ in the city of Maputo and $13.0 \%(194 / 1,492)$ in Manica province. The least number of cases $(2 / 1,492$, equivalent to $0.1 \%$ of total cases) were recorded in the province of Cabo Delgado, followed by Nampula with $0.3 \%(4 / 1,492)$.

\section{Incidence}

With regard to the period 2006 to 2010 , the national average annual crude incidence rate was 1.58 per 100,000 inhabitants. The median annual incidence rate by district was 0.15 (IQ: 0.00-1.43) per 100,000 inhabitants and the maximum rate recorded was 40.08 per 100,000 inhabitants. The highest incidence rates (over the 75 th percentile) were recorded in districts in the provinces of Niassa, Tete, Manica, Gaza, Maputo and the City of Maputo. The majority of districts with high incidence rates border Mozambique's neighboring countries Tanzania, Malawi, Zambia, Zimbabwe, South Africa and Swaziland (Figure 4). The spatial autocorrelation analysis of rates resulted in a Global Moran's index of 0.338 ( $p<0.05$ ), indicating spatial heterogeneity. The same spatial pattern observed for the crude rates was also found when rates were weighted according to the rates of neighboring districts using the Local Empirical Bayesian method. The average Local Empirical Bayesian rate was 1.41 per 100,000 inhabitants. Variation at the district level was 0.00 to 36.99 per 100,000 inhabitants.

\section{Discussion}

Significant advances have been made in controlling and eliminating measles around the world, including increased first dose vaccine coverage, implementation of mass vaccination campaigns, and reinforced measles surveillance through the investigation of cases and establishment of laboratories to confirm diagnoses 19,20,21,22. In Mozambique, routine data from public health services shows an increase in measles vaccination coverage. This increase in routine coverage is consistent with the results found in published coverage studies 23 , reflecting the country's efforts to control and eliminate measles as part of a regional and global response to the disease. The incorporation of spatial analysis of vaccine coverage showed clustering of districts. Strong spatial clustering was observed in 2006 with a reduction in 2003 18. Districts within Quadrant-2 should be given special attention because people living in 
Figure 3

Proportional distribution of measles by age group. Mozambique, 2006-2010 ( $N=1,455)$.

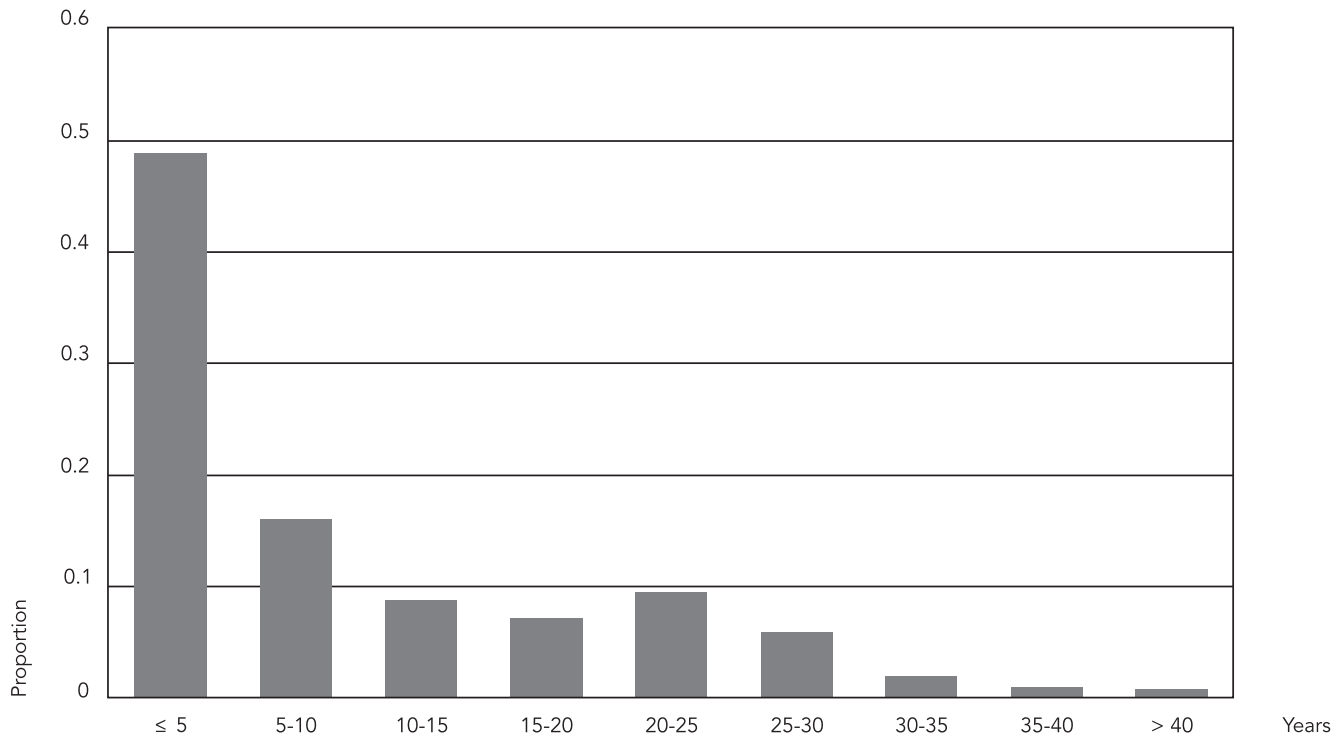

Figure 4

Crude average annual measles incidence per 100,000 inhabitants in the districts of Mozambique, 2006-2010.

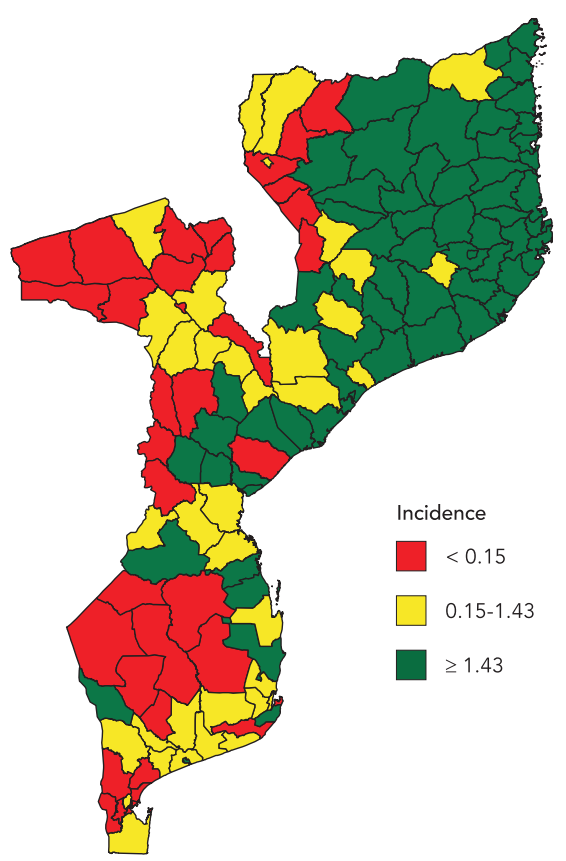


these areas are likely to be more susceptible to measles infection 17 . It should be noted that it was difficult to determine the causes of the spatial patterns 24 and that the identification of these causal factors is an important step towards better decision-making and improving the implementation of measles vaccination programs in this country.

As in other countries, there was a displacement of cases in the young adult age group (20 to 24 years) because reduced viral circulation meant that non-vaccinated individuals, or those who failed to respond to the first doses of measles vaccine, remained susceptible to the disease when they reach adulthood. This group will continue to prove a challenge for measles elimination in Mozambique 25.

Mass vaccination campaigns have an immediate impact on virus circulation, and the results achieved by these campaigns are sustained through routine activities 26 . A reduction in measles notifications after mass vaccination has also been observed in other parts of the world, such as Iran, Ethiopia and several European countries $27,28,29,30$. The inclusion of a large target group in a nationwide vaccination campaign in Mozambique led to a greater reduction in susceptibility compared to the campaigns implemented in urban areas between 1997 and 1999 5. Since Mozambique's population lives predominately in rural areas $(77 \%)$ and relatively small urban centers (population $<300,000$ ), measles control actions in this country should be improved in both rural and urban areas. The success of campaigns is also dependent upon reaching people with lack of access to vaccination services and those individuals who have not developed immunity to the disease after the first vaccination 30 , who are in turn responsible for maintaining the disease transmission chain.

Campaigns held in Mozambique achieved greater coverage because they employed the following specific strategies: allocation of outreach vaccination teams and mobile brigades to settlements located in remote areas; social mobilization programs directed at health care professionals, community leaders, teachers, journalists and the population in general, with the use of clear messages and specific communication media for each group; involvement of communities, private sector and non-governmental organizations in the preparation and implementation of campaigns; and major government commitment 31 .

A reduction in measles notifications was observed after campaign implementation 28,29,30. Oscillations in average annual notification rates observed in Mozambique reflect variations in susceptibility between the periods compared by this study 26 . The first period (2003 to 2004) was preceded by several years of insufficient coverage 23 , which allowed a rise in the number of susceptible elements. A subsequent fall in susceptible elements with the 2005 campaign led to a reduction in the notification rate for the period 2006 to 2007 . However, after this period, routine coverage remained inadequate, leading to an increase in susceptibility in the period 2009 to 2010 and the 2008 campaign failed to prevent subsequent outbreaks. Children under the age of five were more affected during the outbreaks of 2009 and 2010, which suggests low performance of routine vaccination for measles control in Mozambique 30 . There were a significant number of confirmed cases whose vaccination status was not reported. The absence of vaccine documentation is a challenge to verifying vaccination status, especially in rural areas. A lack of documentation was also found in Ethiopia 29. In such cases, self-reported vaccination history is an aid to evaluation of vaccination programs.

Case investigation with laboratory support shows that rubella and other causes of fever and exanthema have an important influence on the total number of suspected measles cases 32 . Progress made up to this stage in the elimination of measles provides a timely opportunity for an effective integration of rubella and measles control actions in this country ${ }^{33}$. This integration could be achieved through measles and rubella surveillance based on the syndromic approach which, according to Pan American Health Organization (PAHO)/World Health Organization (WHO), is defined by the presence of fever and exanthema or identification of a suspected case of measles or rubella by a health care professional 33 . Epidemiological information for both diseases serves to guide control actions and joint elimination. In the near future, the country should aim to introduce surveillance of congenital rubella syndrome and include the double viral vaccine (measles and rubella) in routine vaccination.

High measles incidence rates in districts bordering neighboring countries constitute a challenge for Mozambique ${ }^{34}$. The free movement of people due to a lack of border protection leads to the entry of individuals bearing the measles virus into the country. Coordinated actions between countries in the region are essential for the continent to achieve measles control and elimination ${ }^{34}$. Inside borders, special attention must be given to migrants, particularly those from countries with limited vaccination, and measles vaccination should be offered to individuals that cannot provide evidence that they have been vaccinated. 
Despite high vaccination coverage in Niassa province over the analyzed period, various districts experienced high measles incidence rates. Nationally, the proportion of cases confirmed in vaccinated groups (15\%) was higher than expected 35 . This study was not able to identify an explanation for the high rate of measles infection in vaccinated groups and it is necessary to evaluate the performance of vaccination programs and assess factors associated with individual vaccine failure 31 . In addition, routine vaccination coverage was inadequate in preventing measles outbreaks. Improvements in measles vaccination coverage through both routine immunization and campaigns aimed at achieving and maintaining > 95\% homogenous coverage 35 are therefore recommended. Mass vaccination must include children from the age of six months, as $16 \%$ of cases of measles infection were in children under nine months of age. Data surveillance should be more completeness, as age and vaccination status were not reported in some notified cases. Despite the limitations of the routine data, the results of this study point toward a reduction of measles morbidity and mortality consistent with findings from studies of other African countries 20.

\section{Resumen}

El objetivo de este artículo fue analizar las acciones de eliminación del sarampión en Mozambique, considerando el impacto del programa de vacunación a lo largo del período de 2000-2011. Se revisaron los datos de vacunación y casos de sarampión, disponibles en el Ministerio de Salud. Se aplicaron análisis de series temporales y técnicas estadísticas de análisis espacial. Las coberturas variaron entre un $82 \%$ y un $99 \%$ por nivel. En las provincias, la Ciudad de Maputo tuvo coberturas por debajo de un 70\%, mientras que la provincia de Niassa tuvo coberturas por encima de un $100 \%$. Las coberturas presentaron un patrón espacial que se modificó con el tiempo. La tasa de incidencia de sarampión en el país fue de un 1,58 (0,00-40,08 distritos) por 100 mil habitantes. Los distritos que tienen fronteras con países vecinos tuvieron una elevadas tasas de incidencia. Las coberturas de rutina son insuficientes y la propagación del sarampión continúa en Mozambique. El país necesita alcanzar coberturas $>95 \%$ en niños menores de un año y que sean homogéneas, mantener las campañas de vacunación, mejorar la vigilancia y el tratamiento de casos.

Sarampión; Vacunación; Cobertura de Vacunación

\section{Contributors}

All authors contributed to study conception and design, and to the drafting and final approval of this article.

\section{Acknowledgments}

We are grateful to the cooperation program of the Mozambique and Brazilian Ministries of Science and Technology for its financial support and to Dr. Julie Cliff for the critical review of the manuscript. 


\section{References}

1. Biellik R, Madema S, Taole A, Kutsulukuta A, Allies E, Eggers R, et al. First 5 years of measles elimination in southern Africa: 1996-2000. Lancet 2002; 359:1564-8.

2. Meheus F, van Doorslaer E. Achieving better measles immunization in developing countries: does higher coverage imply lower inequality? Soc Sci Med 2008; 66:1709-18.

3. Plotkin SA, Orenstein W, Offit PA, editors. Vaccines. 5th Ed. London: Saunders-Elsevier; 2008.

4. Jani JV, Jani IV, Araújo C, Sahay S, Barreto J, Bjune G. Assessment of routine surveillance data as a tool to investigate measles outbreaks in Mozambique. BMC Infect Dis 2006; 6:29.

5. Cliff J, Simango A, Augusto O, van der Paal L, Biellik R. Failure of targeted urban supplemental measles vaccination campaigns (1997-1999) to prevent measles epidemics in Mozambique (1998-2001). J Infect Dis 2003; 187 Suppl 1:S51-7.

6. Uzicanin A, Zhou F, Eggers R, Webb E, Strebel P. Economic analysis of the 1996-1997 mass measles immunization campaigns in South Africa. Vaccine 2004; 22:3419-26.

7. Progress toward measles control - African region, 2001-2008. MMWR Morb Mortal Wkly Rep 2009; 58:1036-41.

8. Progress in global measles control and mortality reduction, 2000-2007. Wkly Epidemiol Rec 2008; 83:441-8.

9. Progress in global measles control and mortality reduction, 2000-2006. Wkly Epidemiol Rec 2007; 82:418-24.

10. World Health Organization. Manual for the laboratory diagnosis of measles and rubella virus infection. $2^{\text {nd }}$ Ed. Geneva: World Health Organization; 2007.

11. Cutts FT, Monteiro O, Tabard P, Cliff J. Measles control in Maputo, Mozambique, using a single dose of Schwarz vaccine at age 9 months. Bull World Health Organ 1994; 72:227-31.

12. Instituto Nacional de Estatística. Estatísticas de Moçambique, 2011. http://www.ine.gov.mz/ (accessed on 20/Jun/2011).

13. Mavimbe JC, Braa J, Bjune G. Assessing immunization data quality from routine reports in Mozambique. BMC Public Health 2005; 5:108.

14. Gimbel S, Micek M, Lambdin B, Lara J, Karagianis $\mathrm{M}$, Cuembelo F, et al. An assessment of routine primary care health information system data quality in Sofala Province, Mozambique. Popul Health Metr 2011; 9:12.

15. Novela M, Matosse M. Manual do Programa Alargado de Vacinação. 2a Ed. Maputo: Ministério da Saúde; 2007.

16. World Health Organization Regional Office for Africa. Guidelines for measles surveillance. Brazzaville: World Health Organization Regional Office for Africa; 2004.

17. Souza WV, Barcellos CC, Brito AM, Carvalho MS, Cruz OG, Albuquerque MF, et al. Empirical bayesian model applied to the spatial analysis of leprosy occurrence. Rev Saúde Pública 2001; 35:474-80.
18. Atanaka-Santos M, Souza-Santos R, Czeresnia D. Spatial analysis for stratification of priority malaria control areas, Mato Grosso State, Brazil. Cad Saúde Pública 2007; 23:1099-112.

19. Scribner RA, Johnson SA, Cohen DA, Robinson W, Farley TA, Gruenewald P, et al. Geospatial methods for identification of core groups for HIV/AIDS. Subst Use Misuse 2008; 43:203-21.

20. Imbiriba ENB, Silva Neto AL, Souza WV, Pedrosa V, Cunha MG, Garnelo L. Social inequality, urban growth and leprosy in Manaus: a spatial approach. Rev Saúde Pública 2009; 43:656-65.

21. Masresha BG, Fall A, Eshetu M, Sosler S, Alleman $\mathrm{M}$, Goodson JL, et al. Measles mortality reduction and pre-elimination in the African region, 20012009. J Infect Dis 2011; 204 Suppl 1:S198-204.

22. Stambos V, Leydon J, Ridell M, Clothier H, Catton M, Featherstone D, et al. Evaluation of the World Health Organization global measles and rubella quality assurance program, 2001-2008. J Infect Dis 2011; 204 Suppl 1:S499-505.

23. Featherstone DA, Rota PA, Icenogle J, Mulders MN, Jee Y, Ahmed H, et al. Expansion of the global measles and rubella laboratory network 2005-09. J Infect Dis 2011; 204 Suppl 1:S491-8.

24. Araújo SN, Dade A, Zacarias MF, Chipembe CS. Relatório preliminar do inquérito sobre indicadores múltiplos, 2008. Maputo: Instituto Nacional de Estatística; 2009.

25. Santos SM. Desigualdades socioespaciais em saúde: incorporação de características da vizinhança nos modelos de determinação em saúde. In: Barcellos C, editor. A geografia e o contexto dos problemas de saúde. Rio de Janeiro: ABRASCO; 2008. p. 165-92.

26. Sniadack DH, Mendoza-Aldana J, Jee Y, Bayutas B, Lorenzo-Mariano KM. Progress and challenges for measles elimination by 2012 in the Western Pacific Region. J Infect Dis 2011; 204 Suppl 1:S439-46.

27. Simons E, Mort M, Dabbagh A, Strebel P, Wolfson L. Strategic planning for measles control: using data to inform optimal vaccination strategies. J Infect Dis 2011; 204 Suppl 1:S28-34.

28. Khetsuriani N, Deshevoi S, Goel A, Spika J, Martin R, Emiroglu N. Supplementary immunization activities to achieve measles elimination: experience of the European Region. J Infect Dis 2011; 204 Suppl 1:S343-52.

29. Zahraei SM, Gouya MM, Azad TM, Soltanshahi R, Sabouri A, Naouri B, et al. Successful control and impending elimination of measles in the Islamic Republic of Iran. J Infect Dis 2011; 204 Suppl 1:S305-11.

30. Mitiku K, Bedada T, Masresha BG, Kegne W, NafoTraoré F, Tesfaye N, et al. Progress in measles mortality reduction in Ethiopia, 2002-2009. J Infect Dis 2011; 204 Suppl 1:S232-8.

31. Ferrari MJ, Grais RF, Bharti N, Conlan AJK, Bjornstad ON, Wolfson LJ, et al. The dynamics of measles in sub-Saharan Africa. Nature 2008; 451:679-84. 
32. Uzicanin A, Zimmerman L. Field effectiveness of live attenuated measles-containing vaccines: a review of published literature. J Infect Dis 2011; 204 Suppl 1:S133-48.

33. Mitiku K, Bedada T, Masresha B, Kegne W, NafoTraoré F, Tesfaye N, et al. The epidemiology of rubella disease in Ethiopia: data from the measles case-based surveillance system. J Infect Dis 2011; 204 Suppl 1:S239-42.

34. Zimmerman L, Rogalska J, Wannemuehler KA, Haponiuk M, Kosek A, Pauch E, et al. Toward rubella elimination in Poland: need for supplemental immunization activities, enhanced surveillance, and further integration with measles elimination efforts. J Infect Dis 2011; 204 Suppl 1:S389-95.
35. Peiter PC, Machado LO, Rojas LI. Saúde e vulnerabilidade na faixa de fronteira do Brasil. In: Barcellos C, editor. A geografia e o contexto dos problemas de saúde. Rio de Janeiro: ABRASCO; 2008. p. 265-78.

36. World Health Organization. Measles vaccines: WHO position paper. Wkly Epidemiol Rec 2009; 84:349-60.

Submitted on $29 / \mathrm{Feb} / 2012$

Final version resubmitted on 24/Jul/2012

Approved on 08/Out/2012 